\title{
NOWCASTING GDP OF BOSNIA AND HERZEGOVINA: A COMPARISON OF FORECAST ACCURACY MODELS
}

Ademir Abdić, Emina Resić, Adem Abdić, Adnan Rovčanin

\section{Abstract}

The paper explores the possibilities of creating an econometric model for making short-term forecasts of the Gross Domestic Product of Bosnia and Herzegovina (GDP of B\&H). Its aim is to determine the most representative and most efficient model for forecasting the quarterly GDP of $B \& H$. This is the first paper that simultaneously compares ARIMA models, bridge models and factor models in three different time periods. All variables are available for the period of 2006q1-2016q4. The final choice of the model for forecasting the quarterly GDP of B\&H was selected on the basis of a comparative analysis of the predictive efficiency of the analysed models. Based on the obtained results, the most efficient model for forecasting quarterly GDP of $B \& H$ is the bridge model, which includes four variables as regressor: Retail sale of other goods, Total loans, Manufacturing and Manufacture of food products.

Keywords: quarterly GDP, forecasting models, unbiased estimator, forecast accuracy

JEL Classification: $E 17, G 3, G 32, C 4, C 83$

\section{INTRODUCTION}

Generally, the GDP of a country is the most comprehensive aggregate measure of all economic activities in the country's economy and is often considered the best measure of the performance of an economy. The country's GDP serves as the basis for the creation and adoption of economic development policies. In an individual country, there are different players, both in financial and real markets, interested in making the timely and reliable GDP forecasts. Miscalculation of GDP forecast leads to unreliable, and not infrequently, wrong decisions and policies that can have immeasurable consequences for a country's economy. The effect of miscalculating the GDP forecast can be reflected on: an inadequate choice of a set of monetary and / or
Ademir Abdić, PhD (corresponding author)

Assistant Professor

School of Economics and Business,

University of Sarajevo

E-mail: ademir.abdic@efsa.unsa.ba

Address: Trg oslobođenja - Alija Izetbegović 1,

71000, Sarajevo, Bosna i Hercegovina

Emina Resić, $\mathrm{PhD}$

Professor

School of Economics and Business,

University of Sarajevo

E-mail: emina.resic@efsa.unsa.ba

Adem Abdić, PhD

Assistant Professor

School of Economics and Business,

University of Sarajevo

E-mail: adem.abdic@efsa.unsa.ba

Adnan Rovčanin, $\mathrm{PhD}$

Professor

School of Economics and Business,

University of Sarajevo

E-mail: adnan.rovcanin@efsa.unsa.ba 
fiscal policy measures of state governments aimed at regulating the market activity; an unprofitable investment of private enterprises, as well as an inadequate and irrational personal consumption. Since the data on GDP are the most important indicators of economic growth, the issue of GDP trends has become a key issue among all macroeconomic indicators. Monetary and fiscal policy decisions affect the economy with a delay, and therefore economic policymakers must know the GDP forecasts. The B\&H Agency for Statistics (BHAS) first published the compiled quarterly forecasts of B\&H'S GDP in June 2013. B\&H'S GDP forecasts for the period 2006-2012 were at the level of the European Community Economic Activity Classification Area (NACE Rev 1.1). To the authors' knowledge, apart from the paper by Čolaković and Hlivnjak (2007), there have been no published professional/scientific papers on the forecasts of GDP of B\&H. In the developed countries, the first GDP forecast is available 30 days after the end of the quarter to which the forecast pertains. For example, the UK and the United States have an average delay of about 26 days, while Latvia, Lithuania, Belgium, Spain, Austria and France provide a flash forecasts with the average delay of about 30 days (Eurostat 2017).

The main purpose of this paper is to explore the possibilities of creating econometric models for producing short-term forecast of the quarterly GDP of $\mathrm{B} \& \mathrm{H}$. The primary research question relates to the analysis and identification of different approaches (methods and models) for forecasting GDP and, in particular, to considering the possibilities and suitability of their application taking into account the specific context of the B\&H economy. In line with the research problem, the primary research question was asked: Which of the analysed models, applicable to the example of $B \& H$, provides the most efficient short-term forecast of the quarterly GDP of $B \& H$ ? Furthermore, three research hypotheses were defined:

- By applying ARIMA models, reliable and efficient forecasts of $B \& H$ 's GDP can be obtained.

- By applying a bridge model, reliable and efficient forecasts of B\&H's GDP can be obtained.

- By applying factor models, reliable and efficient forecasts of B\&H's GDP can be obtained.

Box-Jenkins methodology (1976) was used to construct and find the optimal time series ARIMA model. According to the methodology of Baffigi et al. (2004), more than 20 time series were considered in the classical bridge model, based on the correlation coefficients, of the selected predictor time series. The bridge model uses monthly indicators that are available before the release of the quarterly GDP of B\&H. Using the methodology of Schumacher and Breitung (2008), the factor bridge models were estimated. According to the previous empirical studies, 110 potential series that can be used in the factor bridge models were considered. Factor models are linear multiple regression models in which factor scores are used as a predictor of the time series. When identifying and evaluating the regression model, the selection of the predictor variables (factor scores) in the regression model was made based on the forward method. The final choice of the model for forecasting the quarterly GDP of $B \& H$ was selected on the basis of a comparative analysis of the predictive efficiency of the analysed models for the in-sample period, for the out-of-sample period and for a quasi out-of-sample period.

Our paper is therefore quite unique and expands the existing knowledge about forecasting GDP of $\mathrm{B} \& \mathrm{H}$. In particular, it has considered the problem of selecting a subset of models by using the model selection information criteria and comparison of estimated models for the forecasting purposes. The paper addresses the importance of a practical comparison of econometric models. The present study is the first study that analyses and compares GDP forecasts using three econometric models: ARIMA models, bridge models and factor models in three different time periods. Most researchers have focused on one model. The necessity of considering a collection of models arises in the case of a non-stationary time series and the situation when one attempts to model short series (Duong 1987). Therefore, this study provides an additional insight into how to make the selection of models and compare three models. In the paper, a two-criteria approach is suggested. In the first step, statistical tests were conducted on historical data that ensure using the meaningful explanatory variables and a proper fit (in-sample validation). In the second step, statistical tests of the model's ability to allow the evaluation of forecasting the future GDP (out-of-sample validation) were conducted. Thus, the paper uses a two-criteria approach, while most other papers have used a one-criterion approach.

The first section of the paper provides an overview of the empirical literature on the three forecasting models used. The second section describes the methodology and data used, while in the third section the key research results are presented. Finally, the last section provides directions for economic policymakers and the business decision-makers, as well as recommendations for future research. 


\section{THEORETICAL BACKGROUND}

In the developed countries, there is extensive empirical literature on GDP forecasting using the ARIMA model. Many authors have considered univariate time series models (Çeliku et al. 2010; Wei et al. 2010; Maity and Chatterjee 2012; Shahini and Haderi 2013; Zakai 2014; Wabomba et al. 2016), as well as multivariate time series models (Baffigi et al. 2004; Kuzin et al. 2009; Angelini et al. 2010; Buss 2010; Çeliku et al. 2010; Barhoumi et al. 2011; Cobb et al. 2011; Antipa et al. 2012; Shahini and Haderi 2013; Dias et al. 2015; Dritsaki 2015). Some authors considered time series on an annual basis (Wei et al. 2010; Maity and Chatterjee 2012; Zakai 2014; Wabomba et al. 2016) while others used time series on an annual basis (Baffigi et al. 2004; Nunes 2005; Schumacher and Breitung 2008; Angelini et al. 2010; Buss 2010; Çeliku et al. 2010; Barhoumi et al. 2011; Cobb et al. 2011; Antipa et al. 2012; Shahini and Haderi 2013; Dias et al. 2015; Dritsaki 2015). Among other things, the paper focused on several studies. Stock and Watson (1998) compared 49 univariate forecasting methods and numerous pooling models for forecasting 215 US monthly macroeconomic time series at three forecasting horizons over the period of 1959-1996. Of all the individual methods, the best performance was achieved by autoregressive models with unit root testing. Wei, Bian and Yuan (2010) based forecasting GDP of Chinese province of Shan-xi on the ARIMA model. Using the data from the period of 1952-2007, the $\operatorname{ARIMA}(1,2,1)$ model was created. Comparing the actual and predicted values in 20022007, the results showed that the error between the real value of GDP and the projected value of GDP is within $5 \%$. Using the $\operatorname{ARIMA}(1,2,2)$ model, Maity and Chatterjee (2012) examined the possibility of predicting GDP growth rates for India over the period of 1959-2011. The results of their research showed that the above model is very effective in forecasting the GDP and its growth rate in India. Zakai (2014) investigated Pakistanıs GDP forecasting using annual data from the period of 1953-2012. The best-rated model was the $\operatorname{ARIMA}(1,1,0)$ model, which was used for forecasting for the period 2013-2025. Dritsaki (2015) created a model for predicting real GDP rates of the Greek economy. To this end, she used the Box-Jenkins methodology for the period 1980-2013. Using the $\operatorname{ARIMA}(1,1,1)$ model, real GDP rates for 2015, 2016 and 2017 were predicted. Wabomba, Mutwiri and Fredrick (2016) explored the possibilities of using the ARIMA model for modelling Kenyass GDP for the period 19602012. The $\operatorname{ARIMA}(2,2,2)$ model was chosen as the best forecasting model. This model proved to be adequate and relatively effective in modelling Kenyass annual GDP growth rates and has been used in forecasting
Kenyass GDP over a five-year period.

On the other hand, numerous studies in which GDP predicting has been done using the classical bridge model can be found. Among other things, the paper focused on the following research. Baffigi, Golinelli and Parigia (2004) examined the possibility of using a bridge model to forecast GDP growth in the Eurozone. Using bridge models, the authors predicted the total GDP and GDP components by means of both approaches (both production and expenditure components) for three major Eurozone countries. The paper shows that the national short-term bridge model (one quarter ahead and two quarters ahead) provides better forecast results than benchmark univariate/ multivariate statistical models and a small structural model. Darne (2008) proposed a bridge equation for France's short-term GDP forecast. The bridge equation makes it possible to forecast France's quarterly GDP growth for the current quarter based on monthly business surveys in the industrial and service sectors. The paper showed that taking into account business surveys in the service sector can be useful for forecasting the current rate of GDP growth. Angelini et al. (2008) considered multiple models, including traditional bridge models and dynamic factor models. The main results for the Eurozone countries indicate that monthly bridge models (using monthly releases) are significantly better than quarterly bridge models (using quarterly announcements) and dynamic factor models (which use a large number of announcements). Çeliku et al. (2010) developed a short-term model for forecasting Albaniass quarterly GDP. They evaluated several different seasonal components of ARIMA and bridge models. According to the results of their research, the best forecast is given by the average forecast of all presented models. A similar model for assessing Albaniass GDP was also suggested by Mancellari (2010). Barhoumi et al. (2011) presented a model for predicting quarterly GDP growth rates of France. The model is designed to be used on a monthly basis through the integration of monthly economic information by means of a bridge model for the both GDP (production and expenditure) approaches. The results show that GDP growth rates can be more accurately predicted using expenditure approach components than using production approach components. Antipa et al. (2012) presented a series of models aimed at forecasting the current quarterly rate of GDP growth in Germany. The models are designed to be used on a monthly basis through the integration of monthly economic information across bridge models. They showed that it is possible to obtain reasonably good forecasts of the current quarterly GDP growth rate in anticipation of an official announcement. 
Bessonovs (2014) used various univariate and multivariate econometric techniques to obtain a short-term projection of Latviass GDP and to evaluate the performance of the models used. The paper concludes that factor models and bridge models are the best single models.

Furthermore, Schumacher and Breitung (2008) considered a factor model for the short-term forecasting of German GDP growth using a large number of monthly and quarterly real-time time series. Compared to the factor model based on balanced data, the factor model based on mixed frequencies gives slightly better forecasts. Giannone, Reichlin and Small (2008) developed a formal method for estimating the marginal impact of the published monthly data on the forecast of the current quarter US real GDP growth rates. The econometric model used in this analysis was a dynamic factor model where the factors were estimated in two steps: the principal components were first calculated and then the Kalman filter was used. To predict Germanyss GDP growth, Marcellino and Schumacher (2010) combined the factor model based on a large set of macroeconomic variables and the MIDAS model that takes into account the unbalanced database reported in publications with lags for the high and low frequency indicators. The paper concluded that factor models of estimation do not differ significantly, and that the best forecasts are given by simple MIDAS with a single lag in factors. There is no systematic difference between the static and dynamic factor models in nowcasting. Jovanovic and Petrovska (2010) evaluated the prognostic performance of six different models for short-term forecasting of Macedonian GDP. The comparison was made based on the root mean square error and the mean absolute error of the forecast made one quarter ahead. The results showed that the static factor model outperformed other models and provided evidence that information from a large data set can improve forecasts. Godbout and Lombardi (2012) evaluated the relative performance of the factor model across a variety of samples including the 2008 financial crisis. They constructed a factor model for the forecast of GDP of Japan and its components using 38 series of data (including daily, monthly and quarterly variables) from 1991 to 2010. They reached the conclusion that factor models successfully reflect GDP changes and anticipate turnarounds. Kunovac and Špalat (2014) tested the extent to which the available monthly economic indicators help to assess Croatiass GDP rapidly where a factor model was used. Assessments of model scores indicate that factor models based on the dynamics of a large set of variables give better predictions than reference models. Dias et al. (2015) evaluated the relative performance of several factor models to forecast Portugalss GDP growth using a large set of monthly series. Factor models are considered to have significantly outperformed univariate autoregressive models for the current and short-term forecasts one quarter ahead, while in the longer forecast horizons the benefits are much smaller.

\section{RESEARCH METHODOLOGY}

\subsection{Data collection and sample}

The analysed data refer to the period of January 2006 - December 2016¹. The target variables for forecasting are quarterly GDP of $B \& H^{2}$. In 2016, the GDP of B\&H by production approach was nominally BAM 29.90 billion, which is $4.59 \%$ more than in the previous year. An analysis of the structure of value-added GDP of B\&H in 2016 by activity (NACE Rev. 2) shows that the highest value-added GDP of B\&H was generated in wholesale and retail trade $(G) 13.51 \%$, then in manufacturing $(C)$ $12.37 \%$, and in public administration and defence $(\mathrm{O})$ $8.15 \%$. Only $4.42 \%$ of the value-added was generated in education $(P)$, while a surprisingly small share of value-added was generated in construction (F) 3.94\% and financial activity (K) $3.74 \%$. If we group the activities into manufacturing and service activities, it can be seen that in manufacturing activities, about onethird of value-added was generated in GDP of B\&H (34.75\%), whereas in the case of service activities, two-thirds of value-added in GPD of B\&H (65.25\%) were created. Similar to 2016, in the observed period, the largest value-added in GDP of B\&H was created in wholesale and retail trade $(G)$, then in manufacturing $(C)$, and in public administration and defence $(O)$. Besides, looking into the average structure of valueadded, it can be concluded that in the observed period there were no significant changes in the structure of value-added in GDP of B\&H by activities. The use of quarterly frequencies is determined by the availability of official data. The quarterly time series of GDP of B\&H was partly built by retrieving the published final quarterly BHAS data (2006q1-2016q4), while the data for the 2000q1-2005q4 period were compiled by temporally decomposing the annual data to quarterly data. For this period, data were taken from the research of Čolaković and Hlivnjak (2007).

In the list of potentially useful explanatory variables, in addition to lagged values of $B \& H>s$ quarterly GDP, the values of numerous trade and industrial production indexes, monetary aggregate values (M1) and (M2), stock market indexes BIFX30 and SASX10, etc. were considered. Preliminary analysis on time series data was conducted. The series that showed the 
non-stationary behaviours were transformed into the stationary ones using appropriate transformations. First of all, the available data on the structure of GDP components (production side) published by the BHAS were analysed. The aim was to find a relationship between these timely available monthly/quarterly relevant indicators and the ability to provide useful information for the last quarteris GDP forecast. The related indicators included official short-term statistics, other relevant economic and financial data. All monthly indicators able to provide information within 60 days of the last quarter were taken into account. The analysis of the available indicators was limited to the volume or quantity indicators.

\subsection{Methodology}

Box-Jenkins methodology (1976) was used to construct and find the optimal time series model. The series under consideration must be stationary both in mean and variance. Furthermore, data do not need to have outliers or structural breaks, and deterministic patterns should be removed from the data. The original series of quarterly GDP of B\&H distorted the above assumptions and made the necessary transformations.

According to the methodology of Baffigi et al. (2004), more than 20 time series were considered in the classical bridge model, based on the correlation coefficients, of the selected predictor time series. Time series that satisfied the ADF stationary tests were included in the models. Therefore, the dependent variable in the model is the quarterly GDP index of $B \& H(2010=100)$ and the independent variables are quarterly series that have a correlation coefficient with transformed quarterly GDP at an absolute value greater than 0.8 . The models were built on the sample 2006q1-2014q4. The period 2015q1-2016q4 was used to evaluate the accuracy of forecasts and to compare them. The bridge model used monthly indicators that were available before the release of B\&H's quarterly GDP. The list of indicators suitable for estimating was completed based on economic reasoning but also on the fulfilment of the conditions for indicators to show a statistically significant correlation with the quarterly GDP of B\&H. Data are usually available within 60 days after the end of the reference quarter. The quarterly series are compiled as the average of the corresponding monthly data. The variables selected were also seasonally adjusted as they have significant seasonal effects such as quarterly GDP. The seasonal adjustment method is the same as that used to adjust quarterly GDP and therefore it was applied to lower frequency series. When identifying and evaluating the regression model, the selection of the predictor variables into the regression model was made based on the forward method.

Using the methodology of Schumacher and Breitung (2008), factor bridge models were estimated. According to the previous empirical studies, 110 potential series that can be used in factor bridge models were considered ${ }^{3}$. When selecting a series suitable for factor analysis, various criteria were used, such as the Kinnear-Gray criterion, the Kaiser-Meyer-Olkin measure, and the Bartlett test of sphericity. Factor analysis of principal components was applied, as well as orthogonal varimax rotation of the initial solution.

\section{RESEARCH FINDINGS}

After the stationary quarterly GDP series were obtained, the identification of the ARIMA model that best fits the transformed data was performed. Based on the correlation charts of SACF and SPACF transformed data, a number of different initial ARIMA models were taken into consideration. After the preliminary assessment of the parameters of the initial ARIMA models, based on the Akaike information criterion, three ARIMA models were selected:

- ARIMA3: ARIMA $(4,1,0)$ model,

- ARIMA6: $\operatorname{ARIMA}(0,0,0)(1,1,0)_{4}$ model,

- ARIMA9: ARIMA $(0,1,1)(0,1,0)_{4}$ model.

The summary results of the three analysed ARIMA models are given in Table 1.

The results show that all models are statistically significant at the $95 \%$ confidence level. Based on the graphical representation of the line diagrams of the residuals and the histograms of the residuals, it can be concluded that the residuals do not violate the assumption of stationarity and normality. The JarqueBera test showed that residuals follow a normal distribution at a significance level of $5 \%$. With respect to ACF and PACF plots of the residuals, all sample autocorrelations for the first 24 lags fall within $95 \%$ of the confidence limit, indicating that the residuals are random. Furthermore, the Ljung-Box test confirmed that the autocorrelations of residuals were zero for the first 24 lags and that the analysed models provided an adequate description of the data. Also, BreuschGodfrey LM test confirmed that there is no higherorder autocorrelation among residuals. The results of the Breusch-Pagan-Godfrey test confirm that there is no heteroskedasticity of residuals.

Evaluation and comparison of different ARIMA models were based on the performance of the model in the sample period (2000q1-2014q4) and the 
Table 1. The summary results of the three ARIMA models

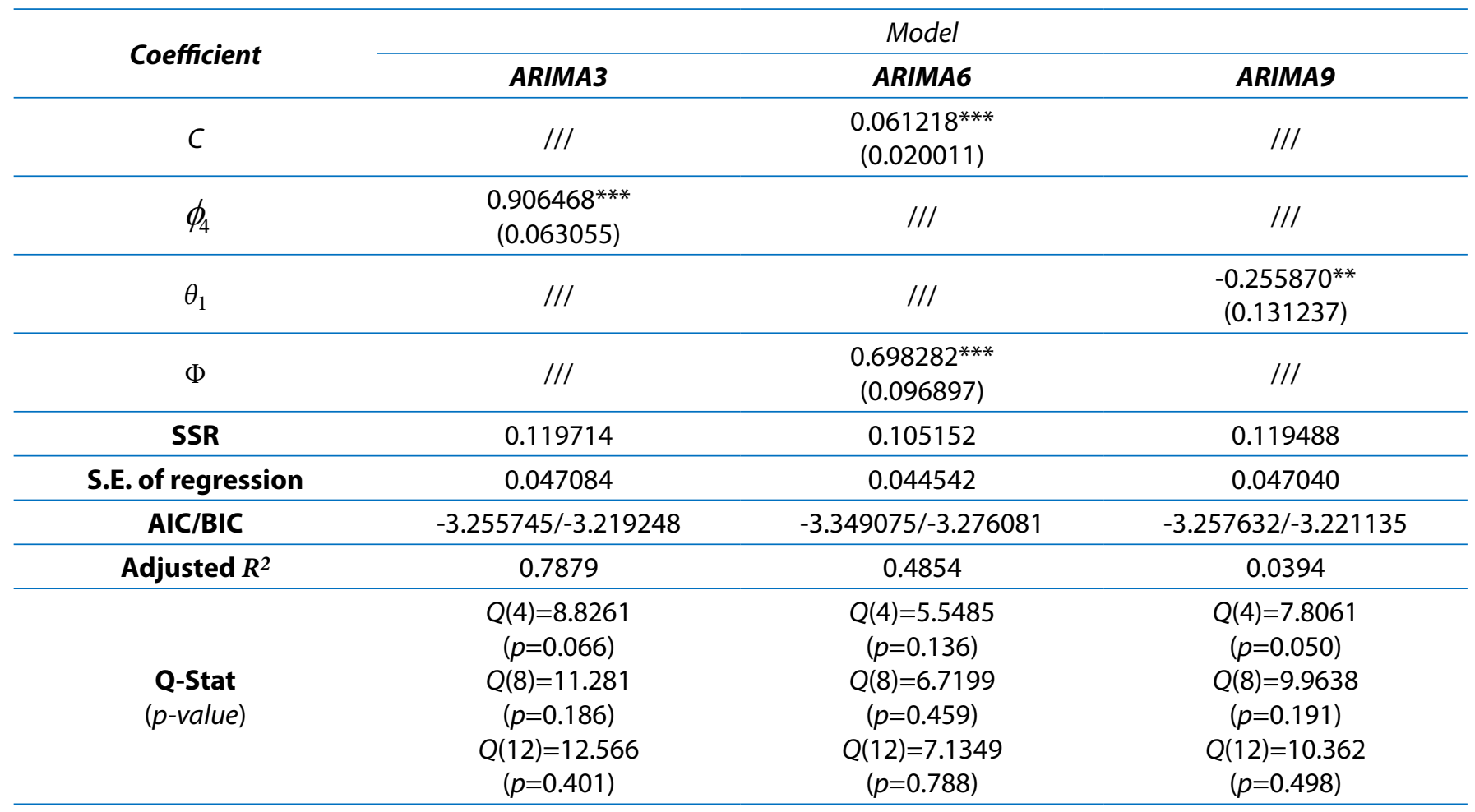

$* * * * * * *$ Significance at the $1 \%, 5 \%$ and $10 \%$ levels, respectively. Standard errors are in parentheses.

Source: Authors' estimates

out-of-sample period (2015q1-2016q4). Numerous measures of forecast accuracy were used to select the best ARIMA forecasting model such as: Root Mean Squared Error (RMSE), Mean Absolute Error (MAE), Mean Absolute Percentage Error (MAPE), Theil coefficient of inequality, variance proportion and covariance proportion. Models that had the best performance across multiple criteria were selected for forecasting. The final selection of the ARIMA model for forecasting B\&H's quarterly GDP was selected based on a comparative analysis of the predictive efficiency of the model for the in-sample and out-of-sample period. The results of the regression analysis of the forecasting error indicate that, with an error risk of $5 \%$, there are no statistically significant errors in the forecasts of the three ARIMA models. In other words, there is no systematic error in the forecasts of these models. The unbiasedness and efficiency of the ARIMA model forecasts were tested using Mincer-Zarnowitz regression. The results of the Mincer-Zarnowitz regression and the Wald test for ARIMA models confirm that the in-sample forecasts obtained from the model with 95\% confidence are unbiased and efficient. Furthermore, the comparison of the accuracy of the forecasts of the models above was done by the Diebold-Mariano test. Based on this test, with a risk of error of $5 \%$, it can be concluded that the average value of the squared differential of forecasting errors is not statistically significantly different from zero. Therefore, it can be concluded that there is no statistically significant difference in the accuracy of the forecasts of the three models described above. The validity of the combination of forecasts using Granger-Ramanathan regression was examined. In the class of ARIMA models, $\operatorname{ARIMA}(0,0,0)(1,1,0)_{4}$ (ARIMA6) was selected as the most efficient model in the quarterly GDP forecasts of B\&H. The construction of $\operatorname{ARIMA}(0,0,0)(1,1,0)_{4}$ model confirmed the first research hypothesis.

Bridge models were built on the period 2006q12014q4. In the bridge model, indicators were used as a predictor of the variable, which with a quarterly index of GDP of B\&H $(2010=100)$ has a degree of correlation greater than 0.8. More than 20 different models were considered based on the form of transformations of the predictor variables. However, as initial KBM models were based on the statistical significance of the model parameters, 10 models were proposed and divided into three subgroups:

- Independent variables are stationary with dlog transform ${ }^{4}$;

- Independent variables are stationary with sddlog transformation ${ }^{5}$;

- The combination of independent variables with dlog transformation and sddlog transformation. 
After a preliminary analysis based on the Akaike information criterion, four models that met all the basic assumptions for the construction of classical bridge models were selected. These are the following models:

KBM4:

$$
\begin{aligned}
& s d d \log K B D P_{t}=\beta_{0}+ \\
& +\beta_{1} s d d \log V 12_{t}+\beta_{2} s d d \log V 311_{t}+\varepsilon_{t}
\end{aligned}
$$

\section{KBM5:}

$$
\begin{aligned}
& s d d \log K B D P_{t}=\beta_{0}+\beta_{1} s d d \log V 12_{t}+ \\
& +\beta_{2} s d d \log V 311_{t}+\beta_{3} s d d \log V 29_{t}+\varepsilon_{t}
\end{aligned}
$$

KBM6:

$s d d \log K B D P_{t}=\left[\begin{array}{l}\beta_{0}+\beta_{1} s d d \log V 12_{t}+\beta_{2} s d d \log V 311_{t}+ \\ +\beta_{3} s d d \log V 29_{t}+\beta_{4} s d d \log V 30_{t}+\varepsilon_{t}\end{array}\right]$

KBM8:

$$
\begin{aligned}
& s d d \log K B D P_{t}=\beta_{0}+\beta_{1} s d d \log V 12_{t}+ \\
& +\beta_{2} \text { sddlogV311 }+\beta_{3} d \log V 325_{t}+\varepsilon_{t}
\end{aligned}
$$

where:

V12 - Retail sale of other goods in s.p.

V311 - Total loans

V29-Manufacturing

V30 - Manufacture of food products

V325 - Other deposits.

The summary results of the four bridge models analysed are given in Table 2 .

Following the same model evaluation procedure, the bridge model that had the best performance across multiple criteria was selected for forecasting. The final choice of the bridge model for forecasting B\&H's quarterly GDP was selected on the basis of a comparative analysis of the predictive efficiency of the model for the in-sample and out-of-sample period. The most effective bridge model in B\&H's quarterly GDP prediction is the KBM6 model, which includes variables as regressor: Retail sale of other goods in s.p., Total loans, Manufacturing and Manufacture of food products. The creation of the above described model confirmed the second research hypothesis.

According to the previous empirical research, 110

\begin{tabular}{|c|c|c|c|c|}
\hline \multirow{2}{*}{ Coefficient } & \multicolumn{4}{|c|}{ Model } \\
\hline & KBM4 & KBM5 & KBM6 & KBM8 \\
\hline$\beta_{0}$ & $/ / /$ & $/ / /$ & $/ / /$ & $/ / /$ \\
\hline$\beta_{1}$ & $\begin{array}{c}0.353798^{* * *} \\
(0.051398)\end{array}$ & $\begin{array}{c}0.276583^{* * *} \\
(0.058710)\end{array}$ & $\begin{array}{c}0.280599 * * * \\
(0.055679)\end{array}$ & $\begin{array}{c}0.307291^{* * *} \\
(0.048238)\end{array}$ \\
\hline$\beta_{2}$ & $\begin{array}{c}0.396261^{* * *} \\
(0.120407)\end{array}$ & $\begin{array}{c}0.3596681^{* * *} \\
(0.113624)\end{array}$ & $\begin{array}{c}0.336891^{* * *} \\
(0.108268)\end{array}$ & $\begin{array}{c}0.470375^{* * *} \\
(0.109755)\end{array}$ \\
\hline$\beta_{3}$ & $/ / /$ & $\begin{array}{c}0.108708^{* * *} \\
(0.047557)\end{array}$ & $\begin{array}{c}0.158923^{* * *} \\
(0.051345)\end{array}$ & $\begin{array}{c}-0.185054^{* * *} \\
(0.062353)\end{array}$ \\
\hline$\beta_{4}$ & $/ / /$ & $/ / /$ & $\begin{array}{c}-0.079694^{* * *} \\
(0.039026)\end{array}$ & $/ / /$ \\
\hline SSR & 0.008967 & 0.007557 & 0.006571 & 0.006821 \\
\hline S.E. of regression & 0.017585 & 0.016429 & 0.015571 & 0.015608 \\
\hline AIC/BIC & $\begin{array}{l}-5.181243 / \\
-5.088727\end{array}$ & $\begin{array}{l}-5.287830 / \\
-5.149057\end{array}$ & $\begin{array}{l}-5.366934 / \\
-5.181904\end{array}$ & $\begin{array}{l}-5.390238 / \\
-5.251465\end{array}$ \\
\hline Adjusted $R^{2}$ & 0.6739 & 0.7154 & 0.7443 & 0.7431 \\
\hline $\begin{array}{c}\text { Q-Stat } \\
(p \text {-value })\end{array}$ & $\begin{array}{c}\mathrm{Q}(4)=6.2969(p=0.178) \\
\mathrm{Q}(8)=6.8155(p=0.557) \\
\mathrm{Q}(12)=7.5891 \\
(p=0.816)\end{array}$ & $\begin{array}{c}\mathrm{Q}(4)=4.5318(p=0.339) \\
\mathrm{Q}(8)=4.9085(p=0.767) \\
\mathrm{Q}(12)=5.7400 \\
(p=0.929)\end{array}$ & $\begin{array}{c}\mathrm{Q}(4)=2.7955(p=0.593) \\
\mathrm{Q}(8)=4.8235(p=0.776) \\
\mathrm{Q}(12)=5.3406 \\
(p=0.946)\end{array}$ & $\begin{array}{c}\mathrm{Q}(4)=5.5426(p=0.236) \\
\mathrm{Q}(8)=8.0930(p=0.424) \\
\mathrm{Q}(12)=8.8529 \\
(p=0.715)\end{array}$ \\
\hline
\end{tabular}
potential series that can be used in factor models have been considered. In line with Kuzin et al. (2012), all considered series were first stationed. The principal component analysis and orthogonal varimax rotation

Table 2. The summary results of the four bridge models

$* * *, * *$, Significance at the $1 \%, 5 \%$ and $10 \%$ levels, respectively. Standard errors are in parentheses.

Source: Authors' estimates 
of the initial solution were applied. Based on the Kaiser criterion, 3 common components were extracted that together explained $73.34 \%$ of the total variability of a given set of series. The first component explained $40.91 \%$, the second component $20.25 \%$ and the third component $12.18 \%$ of the total variability of the initial set of series. The given solution is acceptable because the extracted components explained $73.34 \%$ of the total variability of the initial series. Furthermore, the obtained components were interpreted based on the factor structure matrix. Component 1 is called "trade indexes" and is made up of the following series: Index Retail sale of food, beverages and tobacco in the n.p., Index Retail trade of automotive fuels in the s.p., Index Other retail trade in the n.p., Index Retail trade of other goods in the s.p. and Index Retail trade of other household appliances in s.p.. Component 2 is called "production indexes" and indicates the movement of production in B\&H. Its series are as follows: Index Industrial production total, Index Non-durable consumer goods and Index Manufacturing. Component 3 is called the "financial sector indexes" and it reflects the situation on the B\&H financial market. This component consists of the following series: Index Claims on other sectors of the domestic economy, Index Total loans, Index Total assets and Index Other deposits in foreign currency. Factor models are the linear multiple regression models in which factor scores are used as a predictor of the time series. When identifying and evaluating the regression model, the selection of the predictor variables (factor scores) in the regression model was made on the basis of the forward method. It should be noted that the procedure is repeated before each current forecast. It should also be noted that factors may change over time, as well as the number of factors extracted. The use of the principal component analysis sought to reduce as many series as possible to a number of common factors. The following four models are proposed as initial FBM models based on the statistical significance of the model parameters:

FBM1:

$s d d \log K B D P_{t}=\beta_{0}+\beta_{1} P C A l_{t}+\varepsilon_{t}$

FBM2:

$s d d \log K B D P_{t}=\beta_{0}+\beta_{1} P C A 2_{t}+\varepsilon_{t}$

FBM4:

$s d d \log K B D P_{t}=\beta_{0}+\beta_{1} P C A 1_{t}+\beta_{2} P C A 2_{t}+\varepsilon_{t}$

FBM5:

$s d d \log K B D P_{t}=\beta_{0}+\beta_{1} P C A 1_{t}+\beta_{2} P C A 2_{t}+\beta_{3} P C A 3_{t}+\varepsilon_{t}$

Table 3. The summary results of the four factor models

\begin{tabular}{|c|c|c|c|c|}
\hline \multirow{2}{*}{ Coefficient } & \multicolumn{4}{|c|}{ Model } \\
\hline & FBM1 & FBM2 & FBM4 & FBM5 \\
\hline$\beta_{1}$ & $\begin{array}{c}0.016884^{* * *} \\
(0.004268) \\
\end{array}$ & $\begin{array}{c}0.013866^{* * *} \\
(0.004553) \\
\end{array}$ & $\begin{array}{c}0.016345^{* * *} \\
(0.003567) \\
\end{array}$ & $\begin{array}{c}0.016480^{* * *} \\
(0.003299) \\
\end{array}$ \\
\hline$\beta_{2}$ & /// & /// & $\begin{array}{c}0.013213^{* * *} \\
(0.003530)\end{array}$ & $\begin{array}{c}0.013209^{* * *} \\
(0.003264)\end{array}$ \\
\hline$\beta_{3}$ & /// & /// & $/ / /$ & $\begin{array}{c}0.007907^{* * *} \\
(0.003250) \\
\end{array}$ \\
\hline SSR & 0.008967 & 0.007557 & 0.006571 & 0.006821 \\
\hline S.E. of regression & 0.025337 & 0.027316 & 0.021160 & 0.019566 \\
\hline AIC/BIC & $\begin{array}{l}-4.481355 / \\
-4.435098 \\
\end{array}$ & $\begin{array}{l}-4.330945 / \\
-4.284688 \\
\end{array}$ & $\begin{array}{l}-4.811040 / \\
-4.718525 \\
\end{array}$ & $\begin{array}{l}-4.938305 / \\
-4.799832 \\
\end{array}$ \\
\hline Adjusted $R^{2}$ & 0.3230 & 0.2131 & 0.5278 & 0.5963 \\
\hline $\begin{array}{c}\text { Q-Stat } \\
(p \text {-value })\end{array}$ & $\begin{array}{c}\mathrm{Q}(4)=3.0053(p=0.557) \\
\mathrm{Q}(8)=4.2448(p=0.834) \\
\mathrm{Q}(12)=9.0771 \\
(p=0.696)\end{array}$ & $\begin{array}{c}\mathrm{Q}(4)=1.9676(p=0.742) \\
\mathrm{Q}(8)=3.1033(p=0.928) \\
\mathrm{Q}(12)=6.0825 \\
(p=0.912)\end{array}$ & $\begin{array}{c}\mathrm{Q}(4)=1.0045(p=0.909) \\
\mathrm{Q}(8)=1.5430 \\
(p=0.992) \\
\mathrm{Q}(12)=2.7184 \\
(p=0.997)\end{array}$ & $\begin{array}{c}\mathrm{Q}(4)=2.2701(p=0.686) \\
\mathrm{Q}(8)=2.7151 \\
(p=0.951) \\
\mathrm{Q}(12)=3.9325 \\
(p=0.985)\end{array}$ \\
\hline
\end{tabular}

$* * *, * *, *$ Significance at the $1 \%, 5 \%$ and $10 \%$ levels, respectively. Standard errors are in parentheses.

Source: Authors' estimates 
The summary results of the four analysed factor models are given in Table 3. Following the same model evaluation procedure, a factor model that had the best performance across multiple criteria was selected for forecasting. The final choice of the factor model for forecasting B\&H's quarterly GDP was selected based on a comparative analysis of the predictive efficiency of the model for the in-sample and out-of-sample periods. The FBM5 factor model, which includes three major components, has proven to be the most effective in B\&H's quarterly GDP forecasts, thus confirming the third research hypothesis.

The final selection of the B\&H's quarterly GDP predicting model was selected on the basis of a comparative analysis of the predictive performance of the ARIMA6 model, the KBM6 model and the FBM5 model for the in-sample, out-of-sample and quasiout-of-sample periods. Based on the results, KBM6 has proven to be the most representative and efficient model in B\&H's quarterly GDP forecasts for the in-sample period. Unbiasedness, efficiency, the lowest RMSE, the lowest MAE, and the least MAPE as well as the lowest value of the Theil coefficient of inequality have made the KBM6 model the obvious choice. On the other hand, based on the results, it can be concluded that the best and most efficient out-of-sample period forecasts are provided by the ARIMA6 model, as opposed to the best and most efficient model for the in-sample period. Therefore, given that the out-ofsample period was relatively short (2015q1-2016q4), it was expanded with 8 observations from the in-sample period and the quasi-out-of-sample period obtained (2013q1-2016q4).
Table 4 gives the absolute and relative measures of forecasting errors for all forecasting models used for the in-sample period and quasi-out-of-sample periods. The results of absolute measures of forecasting errors are presented in absolute values, while relative measures are expressed in percentages. The results in Table 4 show that it is very difficult to decide which model is the most representative and most efficient model for forecasting the quarterly GDP of B\&H in the quasi-out-of-sample period. With respect to the measures of forecasting accuracy such as RMSE, Theil inequality index, bias proportion and covariance proportion, the FBM5 model is preferred. On the other hand, the ARIMA6 model has the lowest MAE and MAPE but also the highest bias proportion, indicating that in this model out-of-sample period, the average forecast value differs most from the average of the actual series. The KBM6 model has the lowest variance proportion, indicating that the KBM6 model variance is the least different from the real series variance, and most of the forecast error is due to random events and does not arise from the model's inability to replicate the average of the real series or its variations.

There are two main reasons why the best forecasting models differ in the in-sample period, in the outof-sample period and the quasi-out-of-sample period. First of all, the out-of-sample period is relatively short and some measures of forecast accuracy are sensitive to large individual changes (this primarily pertains to RMSE). Secondly, the difference may be due to the improvement/deterioration of data quality or to structural breaks, or both. However, the results in Table 4 clearly indicate that the forecasts of all models in the

Table 4. Absolute and relative forecasting error measures of single models***

\begin{tabular}{c|c|c|c|c|c|c|c|c}
\hline Model & \multicolumn{2}{|c|}{ ARIMA6 } & \multicolumn{2}{c|}{ KBM6 } & \multicolumn{2}{c|}{ FBM5 } & \multicolumn{2}{c}{ Naïve benchmark } \\
\hline $\begin{array}{c}\text { Measure of } \\
\text { accuracy }\end{array}$ & In-sample & $\begin{array}{c}\text { Quasi-out- } \\
\text { of-sample }\end{array}$ & In-sample & $\begin{array}{c}\text { Quasi-out- } \\
\text { of-sample }\end{array}$ & In-sample & $\begin{array}{c}\text { Quasi-out- } \\
\text { of-sample }\end{array}$ & $\begin{array}{c}\text { In-sample } \\
\text { Quasi-out- } \\
\text { of-sample }\end{array}$ \\
\hline RMSE & $194,574.90$ & $127,187.00$ & $\mathbf{9 1 , 4 4 4 . 1 4}$ & $116,996.40$ & $117,151.90$ & $\mathbf{1 0 3 , 1 3 1 . 0 0}$ & $338,928.40$ & $160,198.20$ \\
\hline MAE & $139,696.00$ & $\mathbf{7 3 , 1 0 4 . 4 3}$ & $\mathbf{7 1 , 7 6 3 . 5 8}$ & $103,104.20$ & $93,174.24$ & $74,358.48$ & $271,872.10$ & $125,378.40$ \\
\hline MAPE & 2.360334 & $\mathbf{1 . 0 4 9 8 5 1}$ & $\mathbf{1 . 1 3 6 3 3 3}$ & 1.487659 & 1.479633 & 1.07143 & 4.593253 & 1.806795 \\
\hline TI & 0.015526 & 0.008973 & $\mathbf{0 . 0 0 7 0 9 5}$ & 0.008288 & 0.009073 & $\mathbf{0 . 0 0 7 2 9 6}$ & 0.027152 & 0.011254 \\
\hline $\begin{array}{c}\text { Bias } \\
\text { Proportion }\end{array}$ & 0.020369 & 0.138267 & $\mathbf{0 . 0 0 3 7 5 1}$ & 0.007174 & 0.065643 & $\mathbf{0 . 0 0 6 0 7 7}$ & 0.013527 & 0.462572 \\
\hline $\begin{array}{c}\text { Variance } \\
\text { Proportion }\end{array}$ & 0.231402 & 0.00594 & $\mathbf{0 . 0 0 5 3 4 3}$ & $\mathbf{0 . 0 0 0 0 7 6}$ & 0.011701 & 0.000207 & 0.381305 & 0.012052 \\
\hline $\begin{array}{c}\text { Covariance } \\
\text { Proportion }\end{array}$ & 0.748228 & 0.855792 & $\mathbf{0 . 9 9 0 9 0 6}$ & 0.99275 & 0.922656 & $\mathbf{0 . 9 9 3 7 1 7}$ & 0.605167 & 0.525377 \\
\hline
\end{tabular}

***QQuasi-out-of-sample is for the period of 2013q1-2016q4.

Source: Authors' estimates 
Table 5. Absolute and relative forecasting error measures of single model compared to naïve benchmark model

\begin{tabular}{c|c|c|c|c|c|c}
\hline Model & \multicolumn{2}{|c|}{ ARIMA6 } & \multicolumn{2}{c|}{ KBM6 } & \multicolumn{2}{c}{ FBM5 } \\
\hline Measure of accuracy & In-sample & $\begin{array}{c}\text { Quasi-out-of- } \\
\text { sample }\end{array}$ & In-sample & $\begin{array}{c}\text { Quasi-out-of- } \\
\text { sample }\end{array}$ & $\begin{array}{c}\text { In-sample } \\
\text { Quasi-out-of- } \\
\text { sample }\end{array}$ \\
\hline RMSE & 0.57 & 0.79 & 0.27 & 0.73 & 0.35 & 0.64 \\
\hline MAE & 0.51 & 0.58 & 0.26 & 0.82 & 0.34 & 0.59 \\
\hline MAPE & 0.51 & 0.58 & 0.25 & 0.82 & 0.32 & 0.59 \\
\hline TI & 0.57 & 0.80 & 0.26 & 0.74 & 0.33 & 0.65 \\
\hline Bariance Proportion & 0.61 & 0.30 & 0.28 & 0.02 & 4.85 & 0.01 \\
\hline Covariance Proportion & 1.24 & 1.63 & 1.64 & 0.01 & 0.03 & 0.02 \\
\hline
\end{tabular}

Source: Authors' estimates

Table 6. Absolute and relative forecasting error measures of single models compared to BHAS's forecasting in quasi period out-of-sample (2013q1-2016q4)

\begin{tabular}{c|c|c|c|c}
\hline Measure of accuracy & ARIMA6 & KBM6 & FBM5 & Naïve benchmark \\
\hline RMSE & 0.67 & 0.62 & 0.54 & 0.84 \\
\hline MAE & 0.49 & 0.69 & 0.49 & 0.83 \\
\hline MAPE & 0.50 & 0.71 & 0.51 & 0.86 \\
\hline$T I$ & 0.66 & 0.61 & 0.54 & 0.83 \\
\hline Bias Proportion & 0.36 & 0.02 & 0.02 & 1.19 \\
\hline Variance Proportion & 0.09 & 0.00 & 0.00 & 0.19 \\
\hline Covariance Proportion & 1.56 & 1.81 & 1.81 & 0.96
\end{tabular}

Source: Authors' estimates

in-sample and quasi-out-of-sample periods have smaller mean absolute percentage error than the naïve random walk benchmark model.

A comparison of the forecasts of all the previously presented models with the forecasts of the random walk benchmark model is given in Table 5. The results are given as a ratio of the forecast error of the analysed models and the forecast error of the benchmark model. Scores less than 1 indicate that the observed model has a smaller forecasting error than the benchmark model (the exception is the covariance proportion). Based on the results in Table 5, we can see that the forecasts of all the models, both in-sample period and quasi-out-of-sample period, have relatively smaller forecasting errors compared to the naïve random walk benchmark model.

Furthermore, Table 6 shows the results of the comparison between the forecasts of all the previously presented models and the first forecasts published by the B\&H Agency for Statistics in the quasi-out-of-sample period (2013q1-2016q4). The results are given as a ratio of the forecasting error of the analysed models and the forecasting error of the BHAS forecasts.

Based on the results in Table 6, we can see that the ARIMA6 model, the KBM6 model and the FBM5 model in the quasi-out-of-sample period (2013q1-2016q4) give better forecasts of B\&H's quarterly GDP as they have relatively smaller prognostic errors of all types than BHAS forecasts. Lastly, given the following facts, the following can be concluded:

- The out-of-sample period and the quasi-out-ofsample period are relatively short;

- There is no statistically significant difference in the forecasts of all the three models within the sample;

- There is no statistically significant difference in the forecasts of all the three out-of-sample models;

- The KBM6 model had the best performance over the longest comparison period, KBM6 model as the most representative and efficient model in the forecasts of B\&H's quarterly GDP. 
The graphical overview of the forecast values of B\&H's quarterly GDP (000 BAM) in 2017 with the expected standard errors is given below.

Table 7 provides an overview of the forecast quarterly GDP of B\&H for 2017.

Using the KBM6 model, we calculated that in the first quarter of 2017, GDP of B\&H was worth 6.91 billion BAM. This indicates that GDP increased by $3.62 \%$ compared to the same quarter of the previous year, which is 1.12 percentage points higher than the average growth rate in the first quarter for the last 5 years. In the second quarter of 2017, the GDP of B\&H amounted to 7.75 billion BAM, that is, the GDP of B\&H in the II quarter increased by $2.93 \%$ compared to the same quarter of the previous year, which is 0.64 percentage points higher than the average growth rate in the second quarter for the last 5 years. In the third quarter of 2017, the GDP of B\&H reached a record amount of 8.50 billion BAM, that is, the GDP of B\&H in the third quarter increased by $3.22 \%$ compared to the same quarter of the previous year, which is 0.37 percentage points higher than the average growth rates in the third quarter for the last 5 years. In the fourth quarter of 2017, the GDP of B\&H amounted to 7.64 billion BAM, that is, the GDP of B\&H in the fourth quarter increased by $2.37 \%$ compared to the same quarter of the previous year, which is 0.72 percentage points less than the average growth rate in the fourth quarter for the last 5 years.

\section{DISCUSSION AND IMPLICATIONS}

The results are consistent with those of other studies such as Baffigi et al. 2004; Angelini et al. 2008; Cobb et al. 2011; Antipa et al. 2012, which indicates that classical bridge models give a better forecast of quarterly GDP than ARIMA models or factor bridge models. The accuracy of these forecasts was verified by comparison to the benchmark naïve model. The results show that the ARIMA6 model, KBM6 model and FBM5 model give more accurate forecasts than the benchmark naïve model. Research findings are similar to those in Baffigi et al. 2004; Schumacher and Breitung 2008; D'Agostino et al. 2011; Yiu and Chow 2011; Shahini and Haderi 2013; Kunovac and Špalat

Figure 1. Forecast values of B\&H's quarterly GDP (000 BAM) in 2017 by KBM6 model
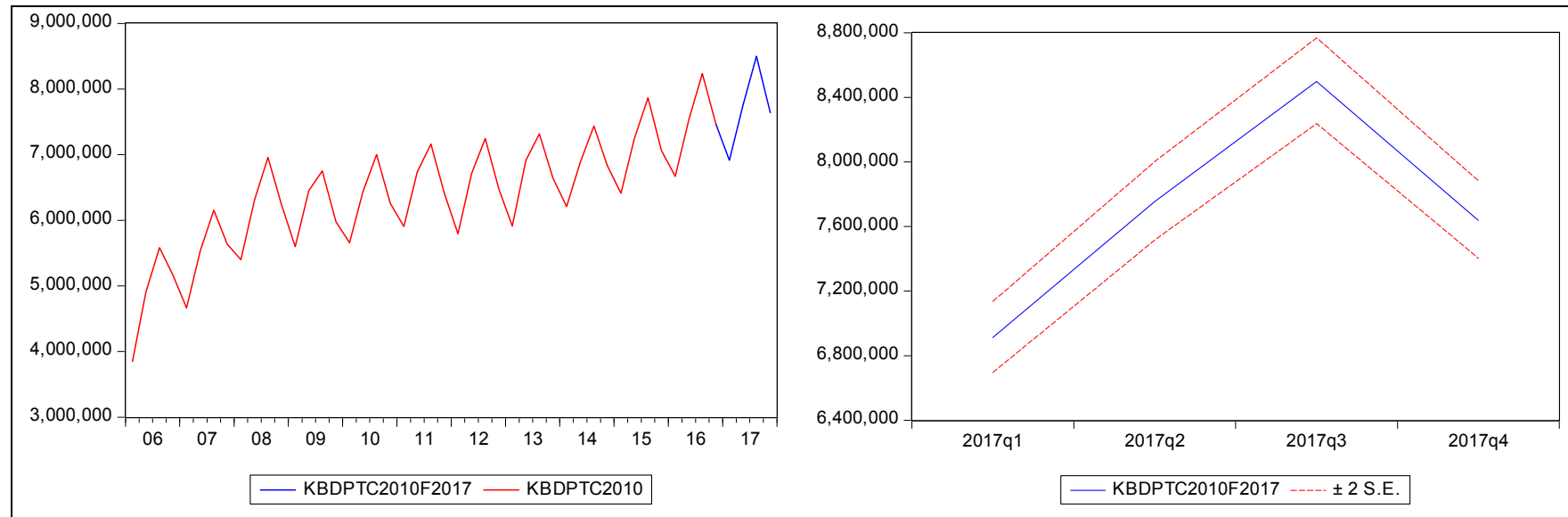

Source: Authors' creation

Table 7. Forecast values of KBDP B\&H (000 BAM) for 2017 by KBM6 model

\begin{tabular}{ccccc}
\hline Quarters & $\begin{array}{c}\text { Lower bound of the } \\
\text { interval }\end{array}$ & $\begin{array}{c}\text { Forecasted } \\
\text { value }\end{array}$ & $\begin{array}{c}\text { Upper bound of the } \\
\text { interval }\end{array}$ & $\begin{array}{c}\text { Forecasted } \\
\text { value (BHAS) }\end{array}$ \\
\hline $2017 q 1$ & $6,700,000.00$ & $6,912,692.88$ & $7,140,000.00$ & $7,074,334.00$ \\
\hline $2017 q 2$ & $7,520,000.00$ & $7,754,968.18$ & $8,000,000.00$ & $7,891,752.00$ \\
\hline $2017 q 3$ & $8,240,000.00$ & $8,498,398.19$ & $8,770,000.00$ & $8,706,847.00$ \\
\hline $2017 q 4$ & $7,400,000.00$ & $7,637,966.57$ & $7,880,000.00$ & n.a. \\
\hline
\end{tabular}

*** Lower and upper bounds of the interval are determined by using $95 \%$ confidence level.

Source: Authors' estimates 
2014, where the average forecasting error of the GDP forecast obtained by the ARIMA model, the classical bridge model or the factor bridge model is less than the average forecasting error of the naïve benchmark model. Further, the results are consistent with the study Duong (1987), which argued that in most practical situations, a single model is not sufficient for the purpose of analysis, and that several useful models should be considered.

\subsection{Implications on the economic policymakers and the business decision-makers}

Given the specificities of the B\&H economy and development of financial markets, the existence of a large time gap between the end of the current year and the publication of the first GDP announcement with a delay of more than 180 days, as well as a very late announcement of the final GDP values (only at the end of the current year for the previous year), a need arose for exploring the possibility of creating an econometric model of GDP forecasting in B\&H whose forecasts will be available no later than 60 days from the end of the observed quarter.

This paper has considered the most significant empirical forecasts of GPD in the developed countries. The results of empirical research to date have contributed to a better understanding of B\&H's GDP and the creation of assumptions for modelling its shortterm prediction. Furthermore, the expected scientific contribution of the paper is reflected in the fact that this is the first scientific research conducted in B\&H that simultaneously included three groups of models: ARIMA models, bridge models and factor models. The three groups of models are explored in the paper, their comparison is presented and the possibilities of their combination in making forecasts are examined. Since forecasting GDP growth rate is one of the most important issues within an economy, in an applied sense, understanding the process of identifying, estimating, and diagnosing an estimating model becomes a basic prerequisite for making accurate forecasts that allow effective and efficient decisions aimed at improving the overall welfare of the country. Finally, the results of this research are evident in the creation of a reliable and efficient model for the short-term forecast of B\&H's GDP. The created model can be very useful in creating certain fiscal and/or monetary policies of state institutions, and on the other hand, it can be a starting point for the state institutions to create an official econometric model of B\&H's GDP forecasting (The Central Bank of B\&H and Agency for Statistics of $B \& H)$. In addition, this study can help policymakers at all levels of government (state, canton or municipality), as well as business decisions makers on all markets (financial and/or real), to assess and to forecast quarterly GDP of B\&H in order to make adequate political and managerial decisions and to construct investment and financial strategies and policies, but also for individuals planning personal spending.

\subsection{Limitations and future research}

The unavailability and inadequacy of the required data for a number of series of real economic activity during the aforementioned research period was a significant limitation for creating bridge models. Therefore, in order to improve all the created bridge models, access to all data on the trends of the B\&H economy is necessary. First of all, this refers to: industrial producer prices on the domestic market, average consumer prices, consumer price index, foreign trade, investment, construction, tourism, population and labour market data, etc. Besides, it would be interesting to include time series on the expenditure side of GDP in the research, and perhaps also include the GDP of the EU or GDP of the countries with which B\&H has the highest foreign trade ratio. Development of a more efficient forecasting model for B\&H's GDP requires a more intensive cooperation of all state institutions, but also a more proactive role of the B\&H Agency for Statistics. Extending the time series as well as adding new series to the created database will create the preconditions for examining the possibility of applying the blocking approach in forecasting GDP, as well as examining the possibility of applying ECM and/or structural macroeconomic models in forecasting GDP (e. g. VAR models). As it can be seen, by all criteria, no model is better than the other models analysed and the possibility of their conditional combinations should be examined. The biggest limitation of the study was the availability and quality of the data. However, the correct use of statistical techniques for the imputation of missing data and/or transformation of the existing data have overcome the described limitation and provided adequate answers to the research questions.

\section{CONCLUSION}

The paper showed that adequate forecasts of B\&H's GDP can be made using the ARIMA model, bridge model and factor model. In this paper, the possibilities of creating an econometric model for making short-term forecast of B\&H's GDP have been explored. 25 different models were evaluated starting from the 
benchmark naïve model via the ARIMA models and the bridge models to the factor models. The database consisted of more than 100 daily, monthly and quarterly time series. All variables were available for the period 2006q1-2016q4. In the group of ARIMA models, $\operatorname{ARIMA}(0,0,0)(1,1,0)_{4}$ model has been selected as the most efficient model for the quarterly forecasts of B\&H's GDP. The most efficient bridge model for the quarterly forecasts of B\&H's GDP was a model with the following repressor variables: Retail trade of other goods in s.p., Total loans, Manufacturing and Manufacture of food products. As for factor models, 110 potential time series that can be used have been considered. The factor model that included three factor scores has proven to be the most efficient factor model in the quarterly forecasts of B\&H's GDP.

Based on the results, it can be concluded that the forecasts of the ARIMA6 model, KBM6 model and FBM5 model, both for the in-sample period and outof-sample period, produce relatively smaller forecasting errors compared to naïve random walk benchmark model and that they also produce relatively smaller forecasting errors with respect to BHAS forecasts in the quasi out-of-sample period.

The final choice of the model for forecasting quarterly GDP of B\&H was selected on the basis of a comparative analysis of the predictive efficiency of the analysed models for the in-sample period, the out-ofsample period and the quasi out-of-sample period. The study results show that there is no statistically significant difference in the forecasts of all the three models for the in-sample period, that there is no statistically significant difference in the forecasts of all three models for the out-of-sample period, and that the KBM6 model had the best performance over the longest comparison period. Based on the research findings obtained, the bridge model has been implemented since it proved to be the most representative and most efficient model for the quarterly forecasts of B\&H's GDP.

\section{REFERENCES}

Aastveit, K. \& Trovik, T. 2012. Nowcasting Norwegian GDP: The role of asset prices in a small open economy. Empirical Economics, 42 (1): 95-119.

Angelini, E., Bańbura, M. \& Rünstler, G. 2010. Estimating and forecasting the euro area monthly national accounts from a dynamic factor model. Journal of Business Cycle Measurement and Analysis, 1: 1-22

Angelini, E., Giannone, D., Rünstler, G., Camba-Méndez, G. \& Reichlin, L. 2008. Short-term forecasts of Euro area GDP growth. Working Paper Series No. 949, European Central Bank.

Antipa, P., Barhoumi, K., Brunhes-Lesage, V. \& Darné, O. 2012. Nowcasting German GDP: A comparison of bridge and factor models. Working Paper No. 401, Banque de France.

Baffigi, A., Golinelli, R. \& Parigi, G. 2004. Bridge models to forecast the euro area GDP. International Journal of Forecasting, 20(3): 447-460.

Bańbura, M., Giannone, D. \& Reichlin, L. 2010. Nowcasting, Working Paper Series No.1275, European Central Bank.

Barhoumi, K., Darné, O., Ferrara, L., \& Pluyaud, B. 2011. Monthly GDP forecasting using bridge models: Comparison from the supply and demand sides for the French economy. Bulletin of Economic Research, 64(1): 53-70.

Bessonovs, A. 2014. Suite of statistical models forecasting Latvian GDP. Procedia - Social and Behavioral Sciences, 110: 1094-1105.

Box, G. E. P. \& Ljung, G. M. 1978. On a Measure of Lack of Fit in Time Series Models. Biometrika, 65(2): 297-303.

Buss, G. 2010. A note on GDP now-/forecasting with dynamic versus static factor models along a business cycle. MPRA Paper No. 22147, University Library of Munich.

Çeliku, E., Kristo, E. \& Boka, V. 2010. Modelling the quarterly GDP: Role of economic and surveys indicators. Working paper, Central bank of Albania.

Cobb, M., Echavarría, G., Filippi, P., García, M., Godoy, C., González, W., Medel, C. \& Urrutia, M. 2011. Short - term GDP forecasting using bridge models: A case for Chile. Working Papers No. 626, Central Bank of Chile.

D)Agostino, A, Gambetti, L. \& Giannone, D. 2011. Macroeconomic forecasting and structural change. Journal of Applied Econometrics, 28(1): 82-101.

Darne, O. 2008. Using business survey in industrial and services sector to nowcast GDP growth: The French case. Economics Bulletin, 3(32): 1-8.

Dias, F., Pinheiro, M. \& Rua, A. 2015. Forecasting Portuguese GDP with factor models: Pre - and post-crisis evidence. Economic Modelling, 44: 266-272.

Dritsaki, C. 2015. Forecasting Real GDP Rate through Econometric Models: An Empirical Study from Greece. Journal of International Business and Economics, 3(1): 13-19.

Duong, Q.P. 1987. Model selection and forecasting: A semiautomatic approach. In Proceedings of a Symposium in Honor of V.M. Joshi, edited by I. B. MacNeill and G. Umphrey, 29-46. Dordrecht, Netherlands: Reidel Publishers.

Eurostat. 2017. Status report on information requirements in EMU - 2017. Available at: http://ec.europa.eu/eurostat/ en/web/products-eurostat-news/-/EFC-REPORT-2017 (accessed May 29, 2018). 
Giannone, D., Reichlin, L. \& Small, D. 2008. Nowcasting: The real-time informational content of macroeconomic data. Journal of Monetary Economics, 55(4): 665-676.

Godbout, C. \& Lombardi, J. K. 2012. Short-term forecasting of the Japanese economy using factor models. Working Paper Series No. 1428, European Central Bank.

Jovanovic, B. \& Petrovska M. 2010. Forecasting Macedonian GDP: Evaluation of different models for short-term forecasting. Working Paper, National Bank of the Republic of Macedonia.

Kunovac, D. \& Špalat, B. 2014. Brza procjena BDP-a upotrebom dostupnih mjesečnih indikatora. Istraživanja, I-42, Hrvatska narodna banka.

Kuzin, V., Marcellino, M. \& Schumacher, C. 2009. Pooling versus model selection for nowcasting with many predictors: An application to German GDP. Economics Working Papers No. ECO2009/13, European University Institute.

Maity, B. \& Chatterjee, B. 2012. Forecasting GDP growth rates of India: An empirical study. International Journal of Economics and Management Sciences, 1(9): 52-58.

Mancellari, A. 2010. Nowcasting quarterly GDP in Albania. Working paper, Central bank of Albania.

Marcellino, M. \& Schumacher, C. 2010. Factor MIDAS for Nowcasting and Forecasting with Ragged-Edge Data: A Model Comparison for German GDP. Oxford Bulletin of Economics and Statistics, 72(4): 518-550.

Nunes, L.C. 2005. Nowcasting quarterly GDP growth in a monthly coincident indicator model. Journal of Forecasting, 24(8): 575-592.

Schumacher, C. \& Breitung, J. 2008. Real-time forecasting of German GDP based on a large factor model with monthly and quarterly data. International Journal of Forecasting, 24(3): 386-398.

Shahini, L. \& Haderi S. 2013. Short term Albanian GDP forecast: One quarter to one year ahead. European Scientific Journal, 9(34): 198-208.

Stock, J. H. \& Watson, M. W. 2002b. Macroeconomic Forecasting Using Diffusion Indexes. Journal of Business \& Economic Statistics, 20(2): 147-162.

Stock, J.H. \& Watson, M.W. 1998. A comparison of linear and nonlinear univariate models for forecasting macroeconomic time series. NBER Working Paper No. 6607, Cambridge MA.
Wabomba, M.S., Mutwiri, M.P. \& Fredrick, M. 2016. Modeling and Forecasting Kenyan GDP Using Autoregressive Integrated Moving Average (ARIMA) Models. Science Journal of Applied Mathematics and Statistics, 4(2): 64-73.

Wei, N., Bian, K.J. \& Yuan, Z. F. 2010. Analyze and Forecast the GDP of Shaanxi Province Based on the ARIMA Model. Journal of Asian Agricultural Research, 2(1): 34-41.

Yiu, M.S. \& Chow, K.K. 2011. Nowcasting Chinese GDP: Information Content of Economic and Financial Data. Working Papers No. 042011, Hong Kong Institute for Monetary Research.

Zakai, M. 2014. A time series modeling on GDP of Pakistan. Journal of Contemporary Issues in Business Research, 3(4): 200-210.

\section{(Endnotes)}

1 An exception is the data for the GDP of B\&H which are available for the period I quarter of 2000 to IV quarter of 2016.

2 The paper analyses the GDP of B\&H at current prices according to the production approach.

3 The selection of series was based on the previous research such as: Stock and Watson 2002b; Angelini et al. 2010; Schumacher and Breitung 2008; Giannone et al. 2008; Marcellino and Schumacher 2010; Kuzin et al. 2012; Buss 2010; Bańbura et al. 2011; D’Agostino et al. 2011; Yiu and Chow 2011; Godbout and Lombardi 2012; Aastveit and Trovik 2012; Dias et al. 2015; Schumacher and Breitung 2006; Jovanovic and Petrovska 2010; Kunovac and Špalat 2014. A list of all considered time series is available upon request.

4 dlog - the first differential of the log variable

5 sddlog - the first and seasonal differential of the log variable 